\title{
Preliminary Diagnostic Survey on Causes of Prenatal Mortality in Icelandic Cattle
}

\author{
By C. Oddsdottir', J.S. Agerholm ${ }^{L}$, E. Jörundsson ${ }^{2}$, and P. Lind ${ }^{3}$ \\ 'Department of Veterinary Pathobiology, The Royal Veterinary and Agricultural University, Frederiksberg, Den- \\ mark, ${ }^{2}$ Institute for Experimental Pathology, University of Iceland, Reykjavík, Iceland, and ${ }^{3}$ Danish Institute for \\ Food and Veterinary Research, Copenhagen, Denmark.
}

The health status of Icelandic domestic animals is greatly affected by the isolated geographic location of Iceland in the northern Atlantic Ocean and a very restrictive import policy regarding agricultural products and animals, i.e., import of cattle has been prohibited since 1882 . Specifically, several important bovine abortifacients including Brucella abortus, Tritrichomonas fetus, Campylobacter fetus, ssp. venerealis, Leptospira interrogans serovar hadjo, bovine herpesvirus type 1 , and bovine viral diarthoe virus have never been found in Iceland (Sigurdsson 2000).

A diagnostic survey of aborted and prematurely delivered calves in Iceland has never been performed. Therefore, the prevalences of lesions and abortifacients in such a material are unknown. As the aetiology of prenatal mortality in cattle depends on the occurrence of both infectious and non-infectious abortifacients as well as management and environmental factors, studies on the causes of prenatal losses can generally not be adapted from one geographic region to another.

Therefore, a preliminary investigation was conducted to obtain knowledge on the aetiology of prenatal mortality in Icelandic cattle.
Cattle breeders and veterinary practitioners were requested to submit aborted foetuses and stillborn premature calves for free-of-charge laboratory examination at the University of Iceland from March to September 2002. Gestation age was initially estimated by crown-rump length (Noden \& Lahunta 1985) and when available compared to date of insemination. The calves were necropsied and specimens of brain, lung, heart, liver, and foetal placenta were fixed by immersion in $10 \%$ neutral buffered formalin for histological examination. Tissue blocks were prepared by standard procedures, embedded in paraffin, sectioned at $7 \mu \mathrm{m}$ (brain) or $3 \mu \mathrm{m}$ (other tissues), and stained by haematoxylin and eosin. Additional staining methods including McManus' method for glycogen (PAS), Mallory's phosphotungstic acid haematoxylin method (PTAH), Masson's trichrome method, Kossa's method for calcium, Perls' method for iron, and Grocott's method for fungi were applied when indicated by the presence of lesions. Additionally, placental sections with necrotising lesions were examined for antigens of Candida albicans, Aspergillus fumigatus, and Absidia corymbifera by immunohistochemistry according to Jensen (1994). 


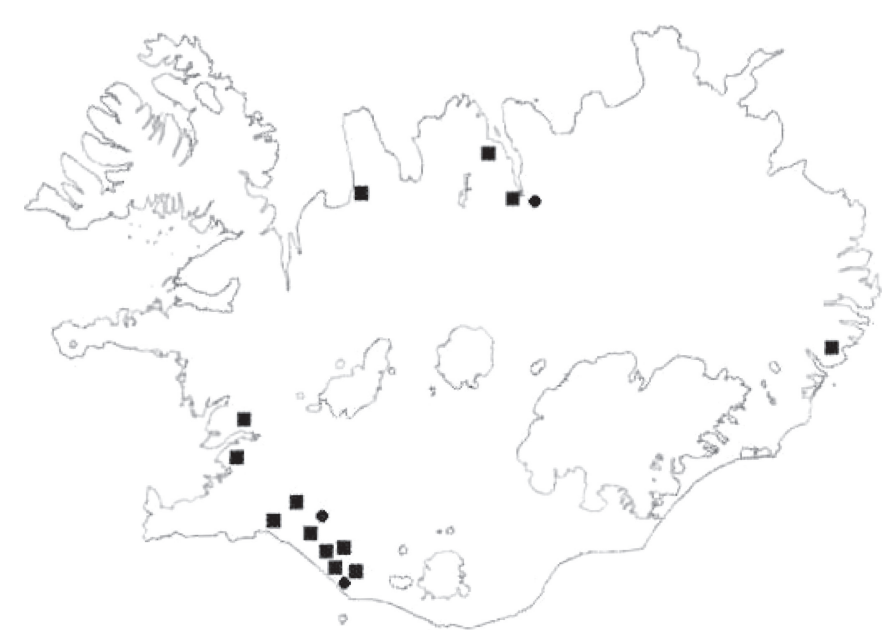

Figure 1. Location of Icelandic cattle herds from which aborted foetuses $(\square)(n=13)$ or premature stillborn calves $(\bullet)(n=3)$ were submitted for laboratory examination.

Bacteriological examination of foetal placenta, lung, liver, and abomasal contents was performed by aerobic and anaerobic incubation on $5 \%$ equine blood agar plates at $37^{\circ} \mathrm{C}$ for $24 \mathrm{~h}$. Identification was based on colony morphology, Gram staining ability, production of catalase and cytochrome $c$ oxidase. Further identification was done by the API system (Bio Mérieux SA, Marcy l'Etoile, France). Mycological examination of foetal placenta was performed by incubation at $32^{\circ} \mathrm{C}$ for at least 5 days on Sabouraud dextrose agar plates. Fungi were identified by microscopic morphology.

Pleural effusion was examined for the presence of antibodies against Neospora caninum by an ISCOM ELISA technique (Slotved et al. 1999). Virological examination was not performed due to the favourable Icelandic disease status.

Only aborted foetuses (gestation age $<260$ days) and stillborn premature calves (defined as 279 days >gestation age $\geq 260$ days) were included in the study. Based on the laboratory findings, each case was categorised in one of four groups according to Agerholm et al.
(1997): Likely cause of abortion identified (group 1), lesions present but specific aetiology not identified (group 2), specific microorganisms isolated from at least 2 tissues without presence of lesions corresponding to the isolated microorganism (group 3), and no likely cause identified (group 4). Groups 1 and 2 represent conclusive diagnostic findings on the aetiology i.e., infection, while group 3 contains cases, where an isolated microorganism may have been the cause of abortion. Group 4 includes cases with an unrecognised cause of abortion. These criteria were also applied on premature calves.

Thirteen aborted foetuses (mean gestation age 228 days, range 177 to 257 days) and 3 stillborn premature calves were submitted for necropsy, The foetal placenta was available for examination in 11 cases. Most foetuses were of dairy breeds and originated from herds located in the major Icelandic agricultural areas (Fig. 1). The cases originated from different herds.

A specific cause of abortion was established in 4 aborted foetuses as Listeria monocytogenes, 
Table 1. Summary of laboratory findings in 13 aborted foetuses and 3 premature stillborn calves in Iceland.

\begin{tabular}{lccc}
\hline & Number of aborted foetuses & Number of premature calves \\
\hline Likely cause identified & 4 & 0 \\
Lesions present, specific aetiology not identified & 3 & 1 \\
Bacteria isolated, lesions not found & 0 & 0 \\
No likely cause identified & 6 & 2 \\
Total & 13 & 3 \\
\hline
\end{tabular}

'From at least 2 tissues

Arcanobacterium pyogenes, Bacillus sp., and Aspergillus fumigatus with corresponding lesions were found with one case each. In further 3 cases, the abortion was likely due to infection as inflammatory changes were observed. These consisted of chronic diffuse pyonecrotising placentitis ( 2 cases) and suppurative bronchopneumonia ( 3 cases). Extensive chronic periacinar hepatic necrosis of unknown aetiology and mild suppurative bronchopneumonia were present in a 213-day-old foetus. A possible cause of abortion or premature delivery was not found in 8 cases of which 2 were mummified foetuses. Pleural effusions of all non-mummified cases were examined for antibodies against $N$. caninum with negative results. The findings are summarised in Table 1 .

The likely cause of prenatal mortality was found in 4 cases (Table 1) corresponding to a diagnostic success rate of $25 \%$. Lesions were present in further four cases giving a morphological diagnosis in $50 \%$ of the examined cases. The diagnostic success rate is lower than in other studies having success rates of around 35\% (Agerholm et al. 1997, Anderson et al. 1990, Caldow et al. 1996, Jamaluddin et al. 1996, Kirkbride et al. 1973). However, the success rate is influenced by the presence of abortifacients in the region i.e., a high prevalence of abortifacients will increase the diagnostic success rate as the relative portion of abortions due to other causes is reduced. Compared to other geographic regions, the health status of Ice- landic cattle is favourable, as several infectious diseases are absent. This will tend to reduce the diagnostic rate. Furthermore, neosporosis was not diagnosed, nor were antibodies against $N$. caninum found. This may indicate that infection due to $N$. cantinum is absent or of low prevalence in Iceland. Further studies, i.e., based on serological screening, are needed to confirm this observation.

The absolute number of cases examined in this study was low. However, compared to the small Icelandic cattle population of approximately 30,000 cows, the relative number is considered relatively high.

The study is the first survey of the causes of prenatal mortality in Iceland and demonstrates, that opportunistic pathogenic bacteria and fungi are the most prevalent causes of abortion in Icelandic cattle. However, a more comprehensive study is needed to obtain more detailed information on prenatal mortality in Icelandic cattle.

\section{Acknowledgements}

The Agricultural Productivity Fund, Iceland is greatly acknowledged for financial support.

\section{References}

Agerholm JS, Willadsen CM, Nielsen TK, Giese SB, Holm E. Jensen L, Agger JF: Diagnostic studies of abortion in Danish dairy herds. 3. Vet. Med. A. 1997, 44, 551-558.

Anderson ML, Blanchard PC, Barr BC. Hoffinan RL: A survey of causes of bovine abortion occurring 
in the San Joaquin Valley, California. J. Vet. Djagn. Invest. 1990, 2, 283-287.

Caldow GL, Buxton D, Spence JA, Holisz J: Diagnoses of bovine abortion in Scotland. Proc. XIX World Buiatrics Congress, 1996, vol. I, 191-194. Jamaluddin AA, Case JT, Hird DW, Blanchard PC, Peauroi JR, Anderson ML: Dairy cattle abortion in California: evaluation of diagnostic laboratory data. J. Vet. Diagn. Invest. 1996, 8, 210-218

Jensen HE: Systemic bovine aspergillosis and zygonycosis in Denmark with reference to pathogenesis, pathology and diagnosis. APMIS 1994, Suppl. 42, 102, 5-48.

Kirkbride CA, Reed DE, Knudtson WU: A diagnostic survey of bovine abortion and stillbirth in the Northern Plains States. J. Amer. Vet. Med. Assoc. 1973, I62, 556-560.

Noden DM, Lahunta A de: The Embryology of Domestic Animals. Williams \& Wilkins, Baltimore, USA. 1985.

Sigurdsson S: Levels of antibodies against infectious diseases in blood of Icelandic cattle. Laboratory results. Not published. 2000.

Slotved HC. Jensen L, Lind P: Comparison of the IFAT and Iscom-ELISA response in bovine fetuses with Neospora caninum infection. Int. J. Parasitol. 1999, 29, 1165-1174.

(Accepted May 13, 2004.)

Reprints may be obtained from: J. S. Agerholm, Department of Veterinary Pathobiology, The Royal Veterinary and Agricultural University, Bülowsvej 17, DK-1870 Frederiksberg C, Dennark. E-mail: jager@kvl.dk, tel: (+45) 352831 17, fax: (+45) 35353514 . 